\title{
One-Versus-All Comparison
}

National Cancer Institute

\section{Source}

National Cancer Institute. One-Versus-All Comparison. NCI Thesaurus. Code C64269.

A type of class comparison used when more than two classes are present in which each class is compared to the other classes as a group. For example Class A is compared to Classes B, C, and D; Class B is compared to Classes A, C, and D, etc. 